\title{
Cerebral Glucose Metabolism in Parkinson's Disease
}

\author{
W.R.W. Martin, J.H. Beckman, D.B. Calne, M.J. Adam \\ R. Harrop, J.G. Rogers, T.J. Ruth, C.I. Sayre, and B.D. Pate
}

\begin{abstract}
Local cerebral glucose utilization was measured in patients with predominantly unilateral Parkinson's disease using ${ }^{18} \mathrm{~F}$-2-fluoro-deoxyglucose and positron emission tomography. Preliminary results indicate the presence of asymmetric metabolic rates in the inferior basal ganglia. The structure comprising the largest portion of basal ganglia at this level is globus pallidus. These findings are consistent with metabolic studies on animals with unilateral nigrostriatal lesions in which pallidal hypermetabolism on the lesioned side has been demonstrated. Increased pallidal activity is likely secondary to a loss of inhibitory dopaminergic input to the striatum from substantia nigra.
\end{abstract}

RÉSUMÉ: Nous avons mesuré l'utilisation locale du glucose dans le cerveau de patients ayant surtout un Parkinson unilitéral. Nous utilisions pour ce faire la tomographie par émission de positron et le ${ }^{18} \mathrm{~F}$-2-fluoro-2-deoxyglucose. Les résultats préliminaires indiquent la présence de taux métaboliques asymmétriques dans les noyaux gris centraux inférieurs, surtout le globus pallidus. Ces résultats sont compatibles avec les études expérimentales chez des animaux avec lésion unilatérale des voies nigro-striées, animaux chez lesquels un hypermétabolisme pallidal avait été noté du côté de la lésion. Cette activité pallidale augmentée est probablement secondaire à la perte des influx dopaminergiques inhibiteurs provenent de la substance noire et agissant au striatum.

Can. J. Neurol. Sci. 1984; 11:169-173

Selective degeneration of nigrostriatal dopaminergic neurons resulting in striatal dopamine depletion is the critical pathological process in Parkinson's Disease (Hornykiewicz, 1972). How this discrete lesion affects the functioning of the basal ganglia neurons, however, is not well understood.

Glucose is the primary substrate required by the brain for energy production. Because the major energy expenditure in the brain is for pumping ions across neuronal membranes (Mata et al., 1980), the mapping of regional cerebral metabolic rate for glucose (CMRG) provides a functional map of brain activity. This may be done in animals using the ${ }^{14} \mathrm{C}$-2-deoxyglucose (DG) autoradiographic method developed by Sokoloff and co-workers (Sokoloff et al., 1977). The technique has been adapted for use with ${ }^{18} \mathrm{~F}$-2-fluoro-2-deoxyglucose (FDG) and positron emission tomography (PET) in man (Phelps et al., 1979). We report here the initial results from an ongoing study in which PET is being used to elucidate the regional CMRG abnormalities in the basal ganglia of patients with unilateral Parkinson's Disease (PD) in order to gain further insight into basal ganglia function and the pathophysiology of PD.

\section{Previous Studies}

Animal models with selective unilateral nigrostriatal lesions have demonstrated variable effects on CMRG in basal ganglia, thalamus and cerebral cortex. These results are summarized in Table 1.

The most constant change noted has been in the globus pallidus ipsilateral to a nigrostriatal lesion. Most authors have observed a unilateral increase in pallidal glucose metabolism (Wooten and Collins, 1981; Kozlowski and Marshall, 1980; Ferron et al., 1979). The degree of increase appears to be time dependent with the maximal rise about 21 days after the acute lesion (Wooten and Collins, 1981). These authors reported that although the degree of pallidal asymmetry decreases after 21 days, as late as 104 days after the acute lesion a $20 \%$ increase in pallidal glucose utilization is still evident. In contrast, Ferron et al. (1979) stated that the transient pallidal increase disappeared by 60 days post-lesioning. Studies by Schwartz et al. (1976) showed no pallidal changes, but these studies were performed only 3 days after lesioning. Ungerstedt (1971) has reported that several days are required for full depletion of striatal dopamine after nigrostriatal lesions. Schwartz et al. (1976) may then have missed significant changes in the global pallidus by studying the animals too early.

Table 1: Changes in glucose metabolism seen in animals with unilateral nigrostriatal lesions

\begin{tabular}{|c|c|c|c|c|}
\hline & G. Pallidus & Striatum & Thalamus & Cortex \\
\hline Ferron et al. & $\uparrow$ & $\longleftrightarrow$ & * & * \\
\hline Kozlowski and Marshall & $\uparrow$ & $\downarrow$ & $\uparrow$ & $\longleftrightarrow$ \\
\hline Wooten and Collins & $\uparrow$ & $\longleftrightarrow$ & $\longleftrightarrow$ & $\longleftrightarrow$ \\
\hline Schwartz et al. & $\longleftrightarrow$ & $\downarrow$ & $\downarrow$ & $\downarrow$ \\
\hline Sagar and Snodgrass & $*$ & $\longleftrightarrow$ & $*$ & $\longleftrightarrow$ \\
\hline
\end{tabular}

$*$ Not Examined

From the Division of Neurology, Health Sciences Centre Hospital, and the UBC/TRIUMF Program on Positron Emission Tomography, University of British Columbia, Vancouver, B.C.

Reprint requests to: Dr. W.R.W. Martin. Division of Neurology, U.B.C. Health Sciences Centre Hospital, 2211 Wesbrook Mall, Vancouver. B.C. Canada 
The effect of unilateral nigrostriatal lesions on CMRG in the neostriatum is less consistent. In some studies, striatal metabolism is unchanged on the lesioned side (Wooten and Collins, 1981; Sagar and Snodgrass, 1980; Ferron et al., 1979). In others, a decrease in striatal glucose utilization on the same side as the lesion has been observed (Kozlowski and Marshall, 1980; Schwartz et al., 1976).

The effects of dopaminergic stimulation on CMRG in animals with unilateral nigral lesions has been studied. Wooten and Collins (1983) gave the direct dopamine agonist apomorphine to rats with unilateral nigral 6-hydroxydopamine lesions. Apomorphine reduced the ipsilateral elevated pallidal glucose utilization and increased striatal metabolism on the same side. They concluded that apomorphine selectively activated supersensitive dopamine receptors in the ipsilateral striatum, thereby increasing functional activity in striatal neurons and hence increasing striatal metabolism. The initial increased metabolism in the ipsilateral globus pallidus was thought to be consequent upon diminished dopamine in the ipsilateral striatum. Activation of striatal dopamine receptors by apomorphine resulted in a decreased firing rate of pallidal neurons reflected as a decrease in metabolic rate. Similar results were obtained by Kozlowski and Marshall (1980).

Leenders et al. (1983) have reported studies of regional cerebral blood flow and oxygen utilization using PET in patients with predominantly unilateral PD. Five such patients were studied. Both oxygen utilization and blood flow were increased in the basal ganglia region of the affected hemisphere (contralateral to the symptomatic limbs). The mean increase was $19.4 \%$ (range $12-56 \%$ ) as compared to the unaffected hemisphere. No significant cortical asymmetry was noted. The findings were thought to be analogous to the above animal studies with disinhibition occurring on the affected side as a result of damaged nigrostriatal pathways. The transverse resolution of the ECAT II tomograph used by this group does not permit separation of globus pallidus from the neostriatum.

\section{Methods}

This is a preliminary report on the results of an on-going study concerning changes in regional cerebral glucose metabolism in patients with unilateral Parkinson's disease. We have studied six such patients. This report deals with four patients one was rejected because of difficulties with head positioning, and one because of problems encountered in collecting data.

Positron emission tomography was performed with the PETT VI system at the Health Sciences Centre Hospital, U.B.C. This system permits emission data to be collected simultaneously from seven contiguous transverse slices, each about $14 \mathrm{~mm}$ in thickness. Studies were done in the high resolution mode, yielding a transverse resolution of about $8 \mathrm{~mm}$.

Patient preparation included the percutaneous insertion of a radial artery catheter under local anesthesia to permit frequent sampling of arterial blood. An intravenous radio-tracer injection was given in the opposite arm. The head was positioned with the aid of a vertical laser line so that the centre of the lowest transverse slice corresponded to the patient's orbitomeatal line. A molded thermoplastic face mask prevented major head movements during the scan. After the head was in place, a transmission scan was performed with a ring phantom containing ${ }^{68} \mathrm{Ge}$ for attenuation correction. During the period of tracer uptake, sensory stimulation was minimized by darkening the scanning room, covering the patient's eyes, and keeping the room as quiet as possible. The ears were not covered.

Production of ${ }^{18} \mathrm{~F}-\mathrm{F}_{2}$ was performed with a $\mathrm{CP}-42$ cyclotron (The Cyclotron Corporation, Berkeley, CA) using the nat $\mathrm{Ne}(\mathrm{p}$, $x)^{18} \mathrm{~F}$ reaction. Sterile and pyrogen-free ${ }^{18} \mathrm{~F}$-2-fluoro-2-deoxyglucose was prepared from ${ }^{18} \mathrm{~F}$ - acetyl hypofluorite as described by Adam (1982). Each patient received about $2.5-3.0 \mathrm{mCi}$ of labelled compound.

For the measurement of regional CMRG, an emission scan (scan length, 10-15 $\mathrm{min}$ ) was performed about $40 \mathrm{~min}$ following FDG injection. The patient's position was then shifted by $7 \mathrm{~mm}$ (one-half of the slice thickness) and a second emission scan was performed. A series of arterial blood samples was drawn starting immediately after injection and continuing until the completion of the scan. These samples were subsequently centrifuged and the plasma radioactivity measured. Blood samples for plasma glucose determination were drawn before and after the scan. Calibration of the tomograph to obtain the regional isotope concentration was performed by imaging a flood phantom containing a known concentration of either ${ }^{18} \mathrm{~F}$ or ${ }^{68} \mathrm{Ga}$. The blood curve and scan data were analyzed using the 3-compartment model initially developed by Sokoloff et al. (1977) and subsequently modified by Phelps et al. (1979). Brooks' (1982) method of calculation was adopted. Literature values (Phelps et al., 1979) for the kinetic rate constants and for the lumped constant were used. This method enables the calculation of regional CMRG in mg. $\mathrm{min}^{-1} \cdot 100 \mathrm{~g}^{-1}$.

The reconstructed images were displayed in a color-coded fashion on a video monitor. By comparing the transverse images to the appropriate slices cut on a $0^{\circ}$ angle in a standard atlas of neuroanatomy (Hanaway et al., 1980), circular regions-of-interest were placed on the thalamus, basal ganglia, and cerebral cortex. Local CMRG values from these regions were used to calculate the degree of asymmetry (abnormal side/normal side) in each region

\section{RESULTS}

Clinical and metabolic data from all patients are summarized in Table 2. The most striking finding was the asymmetry in the inferior region of the basal ganglia; the affected side (i.e. contralateral to the affected limbs) showed increased metabolism. The degree of asymmetry corresponded approximately to the severity of disease with the most severely affected patient having a 54\% increase in metabolic rate on the affected side compared with the unaffected side. In the least affected patient, no asymmetry was noted. Higher sections through basal ganglia were symmetric in all patients. No consistent asymmetries were noted in either the thalamus or the cerebral cortex.

These findings are in contrast to the normal situation in which basal ganglia, thalamus, and cerebral cortex CMRG are all symmetric. Figure 1 illustrates the results from a section through the inferior basal ganglia region in a normal subject and a Parkinson's patient.

The horizontal level in which these asymmetries were noted is illustrated in Figure 2A. We found that precise head positioning was essential for correct interpretation of the scan data. Even a small degree of head tilt such as that illustrated in Figure $2 \mathrm{~B}$ will result in the basal ganglia on one side only being included within the slice and lead to the appearance of increased metabolism on that side. The presence and degree of head tilt may be 
readily assessed from the appearance of the cerebral outline in the lower slices through the tips of the temporal lobes and the posterior fossa. Patients in whom we observed these basal ganglia metabolic asymmetries did not have head tilt.

\section{Discussion}

The basal ganglia asymmetries seen are evident primarily in the sections containing the lower portion of the basal ganglia. Anatomically, the specific structure which would comprise the largest portion of basal ganglia at this level is globus pallidus. Higher sections through basal ganglia would include much less pallidal contribution, but more of neostriatum. Our findings, then, are consistent with the animal data and suggest pallidal hypermetabolism on the side of the most affected nigrostriatal pathway. The absence of major asymmetries in cerebral cortex, thalamus, and striatum is also consistent with most of the animal studies.

Dopaminergic input to the striatum from substantia nigra is felt to be inhibitory (Siggins et al., 1976). Loss of the input in Parkinson's disease would logically lead to increased activity in deafferented striatal regions. The major efferent pathway from striatum is to globus pallidus. Striato-pallidal fibers are thought to produce GABA-mediated inhibition in the pallidum (Fahn, 1976). Two alternate mechanisms to explain the pallidal hypermetabolism are proposed. One possibility is that it reflects increased firing in the terminal fields of disinhibited striatopallidal neurons. In support of this view, Mata et al. (1980) have

Table 2: Clinical and metabolic data from four parkinsonian patients

\begin{tabular}{|c|c|c|c|c|c|c|c|c|}
\hline \multirow[b]{2}{*}{ Patient } & \multirow[b]{2}{*}{ Age/Sex } & \multirow[b]{2}{*}{$\begin{array}{l}\text { Duration } \\
\text { (Yrs) }\end{array}$} & \multirow[b]{2}{*}{ Severity } & \multicolumn{4}{|c|}{ Basal Ganglia } & \multirow[b]{2}{*}{$\begin{array}{c}\text { Cortex } \\
(\mathrm{C} / \mathrm{I})\end{array}$} \\
\hline & & & & $\begin{array}{c}\text { Side } \\
\text { Affected }\end{array}$ & $\begin{array}{c}\text { Upper } \\
(\mathbf{C} / \mathbf{I})\end{array}$ & $\begin{array}{c}\text { Lower } \\
\text { (C/I) }\end{array}$ & $\begin{array}{c}\text { Thalamus } \\
(\mathbf{C} / \mathbf{I})\end{array}$ & \\
\hline J.R. & $70 \mathrm{M}$ & 3 & Moderate & $\mathbf{R}$ & 1.03 & 1.18 & 1.01 & 1.00 \\
\hline F.S. & $55 \mathrm{M}$ & 9 & Severe & $\mathrm{L}$ & .924 & 1.54 & .918 & 1.08 \\
\hline E.D. & $79 \mathrm{~F}$ & 16 & Severe & $\mathrm{L}$ & 1.00 & $*$ & .967 & .980 \\
\hline A.B. & $63 \mathrm{~F}$ & 2 & Mild & $\vec{R}$ & .927 & .945 & .966 & .961 \\
\hline Normal & - & - & - & - & 1.03 & 1.04 & 1.02 & .940 \\
\hline
\end{tabular}

$\mathrm{C} / \mathrm{I}=\frac{\text { metabolic rate glucose contralateral to affected limb }}{\text { metabolic rate glucose ipsilateral to affected limb }}$

* - not identified due to positioning

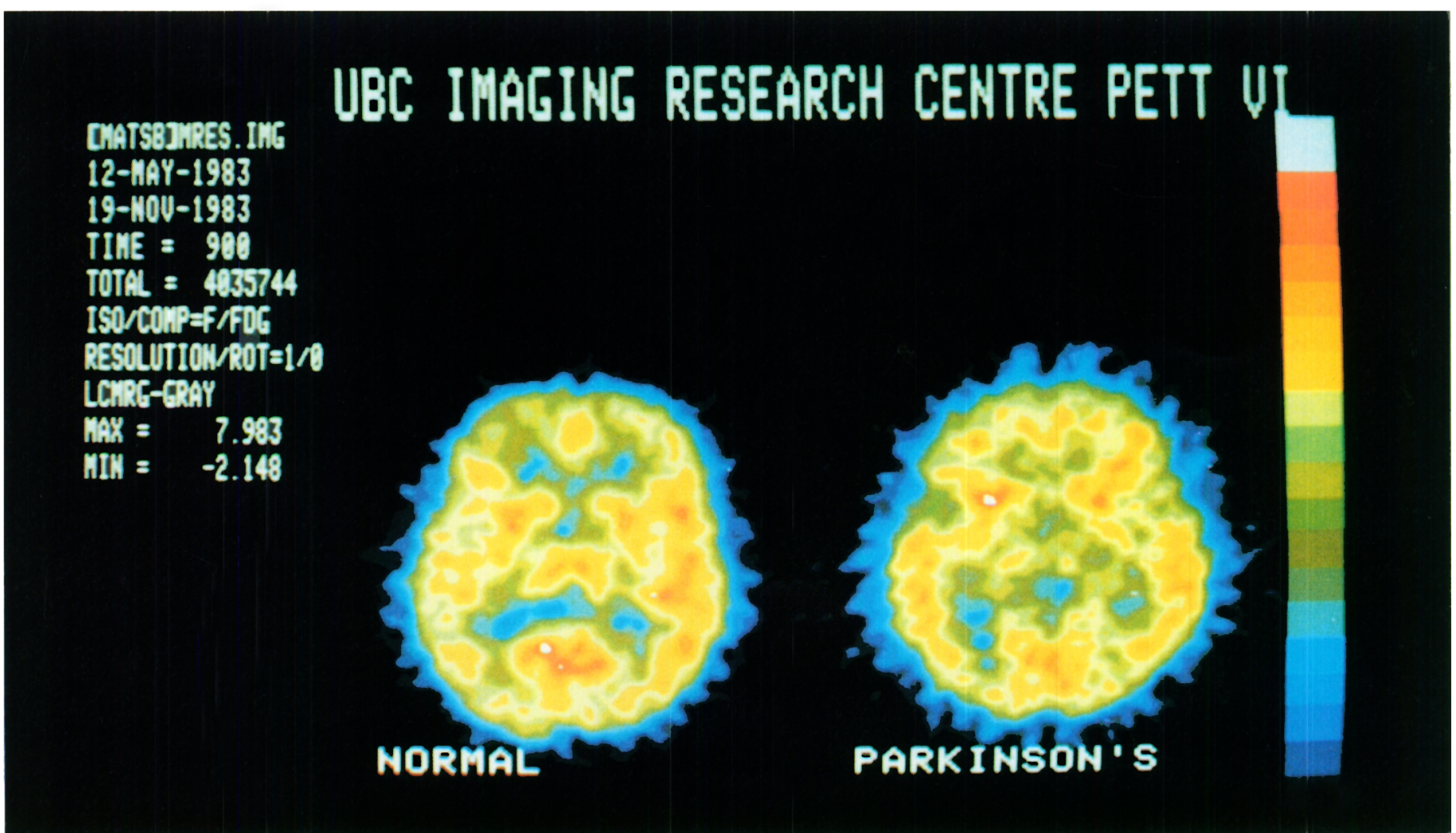

Figure I - A horizontal section through lower basal ganglia in a normal subject and a patient with unilateral Parkinson's disease (J.R. in Table 2). The left side of the brain is on the left side of the illustration. The CMRG corresponds to the color scale with white marking the area of highest metabolic rate. 
A

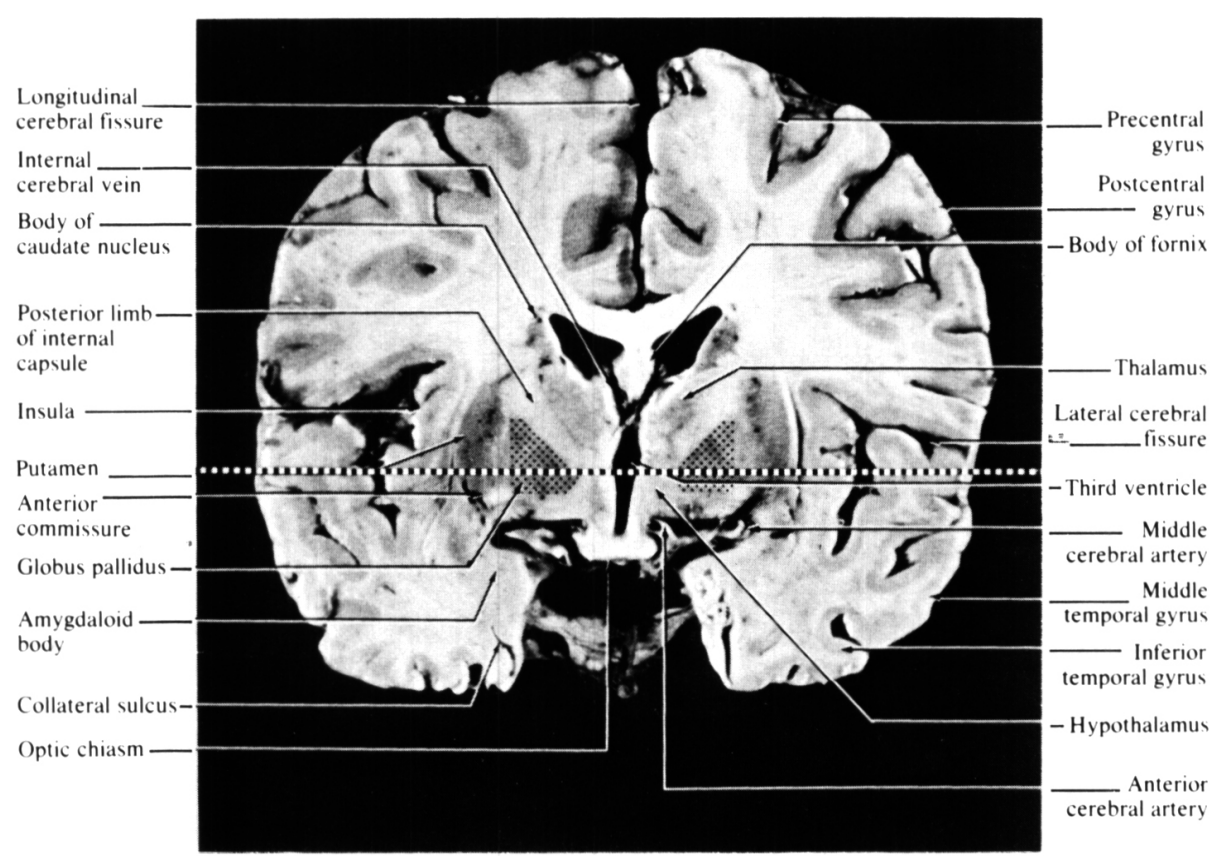

B

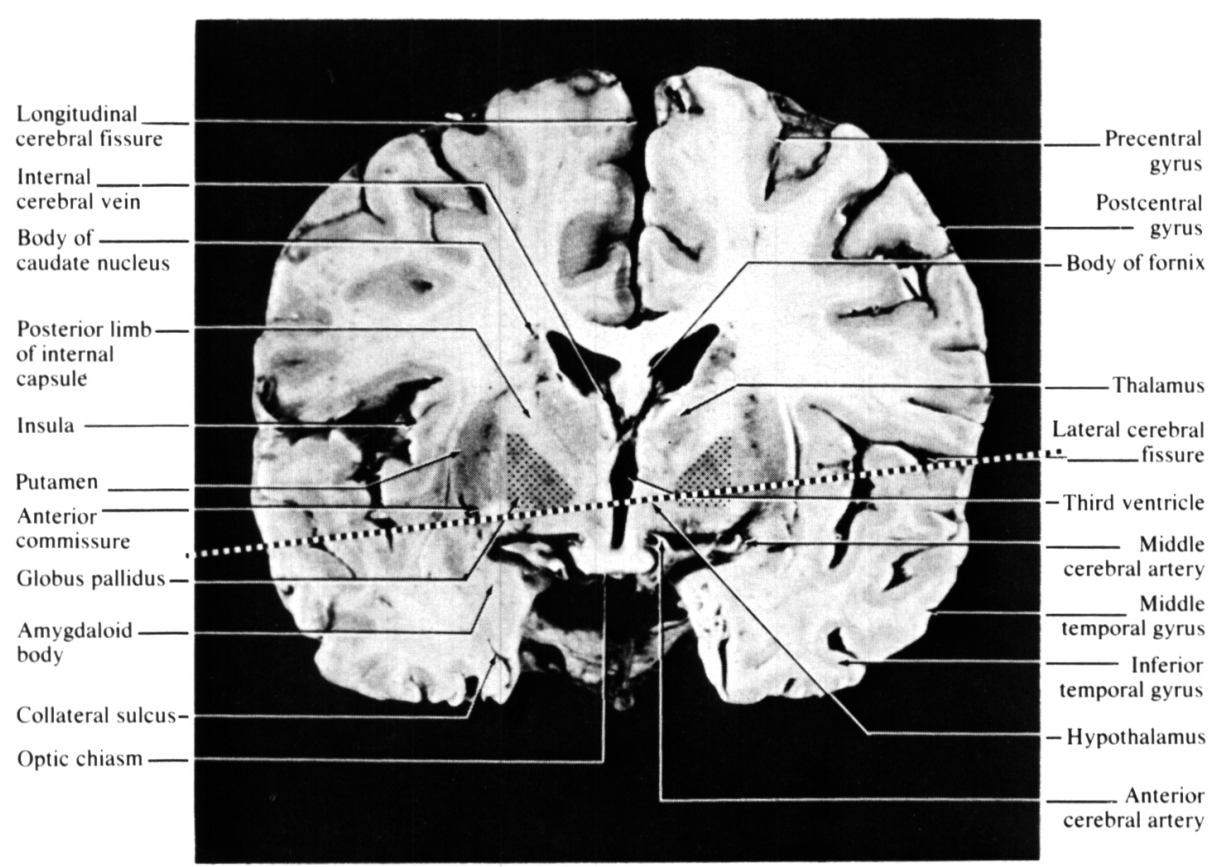

Figure $2-A$ ) coronal section with the level of the lower basal ganglia marked. The major asymmetries were seen at this level where globus pallidus comprises a large portion of basal ganglia (modified from Binder et al., 1979). B) coronal section illustrating basal ganglia positioning relative to a horizontal section in a subject with improper head positioning (modified from Binder et al., 1979). 
concluded that the greatest increase in glucose utilization following stimulation is in nerve endings and dendrites where surface-to-volume ratios are high. A second possibility is that the hyperpolarization in pallidal neurons which results from GABA-mediated inhibition requires sufficient energy to generate the differences observed in FDG accumulation.

The degree of hypermetabolism demonstrated correlates approximately with the severity of parkinsonian symptomatology. This would be in accord with the concept of increased disinhibition resulting from progressive loss of neurons in the substantia nigra. Asymmetry of symptomatology and asymmetry of pallidal metabolism may both be consequent upon asymmetry of the underlying pathological process. If this view is correct, it would be expected that patients with bilateral clinical involvement would have bilateral pallidal hypermetabolism. In order to demonstrate this with PET, pallidal metabolic rate must be significantly greater than normal. Leenders et al. (1983) have reported that although the more abnormal basal ganglia in unilateral parkinsonian patients have a significantly higher metabolic rate compared to the other side, values on both sides remained within the normal range. We have commenced studies with FDG and the high-resolution PETT VI on patients with equal, bilateral clinical involvement to confirm or refute our hypothesis.

We have encountered two major difficulties in this study. The presence of even a slight tilt in head position will result in asymmetric partial volume effects in the basal ganglia and may thus produce artifactually asymmetric basal ganglia metabolism. We have modified the head positioning technique with a double laser system to eliminate this problem.

The second difficulty is in the identification of anatomical structures. We have developed a system in which images from CT, NMR, and PET may be displayed with a common pixel size on the same monitor. A region-of-interest outline may then be placed on an anatomical study such as CT or NMR and the metabolic rate from the PET study can automatically be determined for the same region. In this way, anatomical structures the size of the globus pallidus can be studied with improved accuracy.

Further insights into the pathophysiology of the basal ganglia in Parkinson's disease are likely to accrue from PET studies on regional CMRG. In addition, recent developments permit study of dopamine metabolism with the use of radio-labelled DOPA analogs (Garnett et al., 1983) and of dopamine receptors with labelled dopamine antagonists (Wagner et al., 1983). These developments should lead to better understanding of the natural history and physiology of parkinsonism; they are also likely to have an impact on management.

\section{ACKNOWLEDGEMENTS}

This work was supported in part by grants from the Medical Research Council of Canada and from the Dystonia Medical Research Foundation.

\section{REFERENCES}

Adam MJ (1982) A rapid, stereoselective, high yielding synthesis of 2-deoxy-2-fluor-D-hexopyranoses: reaction of glycals with acetyl hypofluorite. J. Chem. Soc. Chem. Commun. 730.
Binder GA, Haughton VM, Ho K-C (1979) Computed Tomogaphy of the Brain in Axial, Coronal, and Sagittal Planes. Little, Brown and Company: Boston.

Brooks RA (1982) Alternative formula for glucose utilization using labeled deoxyglucose, J. Nucl. Med. 23: 538-539.

Fahn S (1976) Biochemistry of the basal ganglia. Adv. Neurol. 14: 59-89.

Ferron A, DesRosiers MH, de Montigny C, Bosler O, Reader TA, Descarries L (1979) Effects of unilateral destruction of the nigrostriatal dopamine system on local cerebral glucose utilization in adult rat. Soc. Neurosci. Abstr. 5: 70.

Garnett ES, Firnau G, Nahmias C (1982) Dopamine visualized in the basal ganglia of living man. Nature 305: 137-138.

Hanaway J, Scott WR, Strother CM (1980) Atlas of the Human Brain and the Orbit for Computed Tomography. Warren H. Green Inc.: St. Louis, Missouri.

Hornykiewicz O (1972) Neurochemistry of parkinsonism. In: Handbook of Neurochemistry 7, A. Lajtha, ed., pp. 465-501, Plenum Press: New York.

Kozlowski M, Marshall JF (1980) Plasticity of [ $\left.{ }^{14} \mathrm{C}\right] 2$-deoxy-D-glucose incorporation into neostriatum and related structures in response to dopamine neuron damage and apomorphine replacement. Brain Res. 197: 167-183.

Leenders K. Wolfson L, Gibbs J, Wise R, Jones T, Legg N (1983) Regional cerebral blood flow and oxygen metabolism in Parkinson's disease and their response to L-dopa. J. Cereb. Blood Flow and Metabol. 3 (Suppl. 1): S488-S489.

Mata M, Fink DJ, Gainers H, Smith CB, Davidsen L, Savaki H, Schwartz WJ, Sokoloff L (1980) Activity-dependent energy metabolism in rat posterior pituitary primarily reflects sodium pump activity. J. Neurochem. 34: 213-215.

Phelps ME, Huang SC, Hoffman EJ, Selin C, Sokoloff I, Kuhl DE (1979) Tomographic measurement of local cerebral glucose metabolic rate in humans with (F-18)2-fluoro-2-deoxy-D-glucose: validation of method. Ann. Neurol. 6: 371-388.

Sagar SM, Snodgrass SR (1980) Effects of substantia nigra lesions on forebrain 2-deoxyglucose retention in the rat. Brain Res. 185: 335-348.

Schwartz WJ, Sharp FR, Gunn RH, Evarts EV (1976) Lesions of ascending dopaminergic pathways decrease forebrain glucose utilization. Nature 261: 155-157.

Siggins GR, Hoffer BJ, Bloom FE, Ungerstedt U (1976) Cytochemical and electrophysiological studies of dopamine in the caudate nucleus. In: M.D. Yahr (Ed.), Research Communications: Association for Research in Nervous and Mental Disease (The Basal Ganglia), Vol. 55, Raven Press: New York, pp. 227-247.

Sokoloff L, Reivich M, Kennedy C, Des Rosiers MH, Patlak CS, Pettigrew KD, Sakurada O, Shinohara M (1977) The $\left[{ }^{14} \mathrm{C}\right]$ deoxyglucose method for the measurement of local cerebral glucose utilization: theory, procedure, and normal values in the conscious and anesthetized albino rat. J. Neurochem. 28: 897-916.

Ungerstedt $U$ (1971) Stereotaxic mapping of monomine pathways in the rat brain. Acta. Physiol. Scand. 367 (Suppl.): 1-48.

Wagner HN, Burns HD, Dannals RF, Wong DF, Langstrom B, Duelfer T, Frost JJ, Ravert HT, Links, Rosenblood SB, Lukas SE, Kramer AV, Kuhar MJ (1983) Imaging dopamine receptors in the human brain by positron tomography. Science 221: 1264-1266.

Wooten GF, Collins RC (1983) Effects of dopaminergic stimulation on functional brain metabolism in rats with unilateral substantia nigra lesions. Brain Res. 263: 267-275.

Wooten GF, Collins RC (1981) Metabolic effects of unilateral lesions of the substantia nigra. J. Neurosci. 1: 285-291. 